\title{
Left circumflex artery pericardia fistula combined with huge pseudoaneurysm: a rare case report
}

\author{
Zhiyan Shen ${ }^{1,2}$, Kun Xia ${ }^{1,2}$, Xinfeng Liü ${ }^{2}$ and Rongpin Wang ${ }^{2^{*}}$ (1)
}

\begin{abstract}
Background: Coronary artery fistula refers to an abnormal communication between a coronary artery and great vessel, a cardiac chamber or other structure. The left circumflex artery (LCX) pericardia fistula combined with huge pseudoaneurysm is extremely rare.
\end{abstract}

Case presentation: A 39-year-old young female was admitted into our hospital because of palpitation and shortness of breath. Coronary computed tomography angiography (CCTA) showed a huge pseudoaneurysm located in pericardium. Coronary angiography revealed the LCX pericardia fistula. Then surgical treatment was performed. She was in good condition without complications after surgery.

Conclusions: Coronary artery fistula combined with pseudoaneurysm can be caused by congenital factors. Early surgical treatment can relieve the patient's symptoms and prevent the occurrence of adverse cardiovascular events.

Keywords: Circumflex coronary artery, Coronary artery fistula, Pseudoaneurysm

\section{Background}

Coronary artery fistula (CAF) refers to an abnormal communication between a coronary artery and great vessel, a cardiac chamber or other structure [1]. It is rare with an incidence of $0.002 \%$ in the general population but the prevalence is $0.05-0.25 \%$ in patients who undergo coronary angiography [2]. Herein, we described a rare case of young female with both the LCX pericardia fistula and a huge pseudoaneurysm. She was treated successfully by surgery.

\footnotetext{
*Correspondence: wangrongpin@126.com

${ }^{2}$ Department of Radiology, International Exemplary Cooperation Base of Precision Imaging for Diagnosis and Treatment, NHC Key Laboratory of Pulmonary Immune-related Diseases, Guizhou Provincial People's Hospital, No. 83 Zhongshan East Road, Nan Ming District, Guiyang 550002, Guizhou Province, China

Full list of author information is available at the end of the article
}

\section{Case presentation}

A 39-year-old young female with no history of heart disease was admitted with palpitation, shortness of breath for 2 years and aggravation for 6 months. On admission, her blood pressure was $110 / 60 \mathrm{mmHg}$ and her heart rate was 68 beats/min without cardiac murmurs. Her lower limb were not swollen. Electrocardiogram and laboratory examinations were normal range.

Chest radiography revealed that her cardiac shadow was enlarged to the left. Echocardiography showed a mass of the pericardium. Coronary computed tomography angiography (CCTA) demonstrated that the distal segment of the LCX was significantly dilated with contrast agent filling and with huge thrombi (Fig. 1a) in the pericardium. Volumetic reconstruction showed that distal segment of the LCX were remarkably dilated (Fig. 1b). The left anterior descending branch and left coronary trunk were normal. The patient underwent the coronary angiography and selective micro catheter angiography of the LCX, which revealed a distal fistula of the

(C) The Author(s) 2021. Open Access This article is licensed under a Creative Commons Attribution 4.0 International License, which permits use, sharing, adaptation, distribution and reproduction in any medium or format, as long as you give appropriate credit to the original author(s) and the source, provide a link to the Creative Commons licence, and indicate if changes were made. The images or other third party material in this article are included in the article's Creative Commons licence, unless indicated otherwise in a credit line to the material. If material is not included in the article's Creative Commons licence and your intended use is not permitted by statutory regulation or exceeds the permitted use, you will need to obtain permission directly from the copyright holder. To view a copy of this licence, visit http//creativecommons.org/licenses/by/4.0/. The Creative Commons Public Domain Dedication waiver (http://creativecommons.org/publicdomain/zero/1.0/) applies to the data made available in this article, unless otherwise stated in a credit line to the data. 


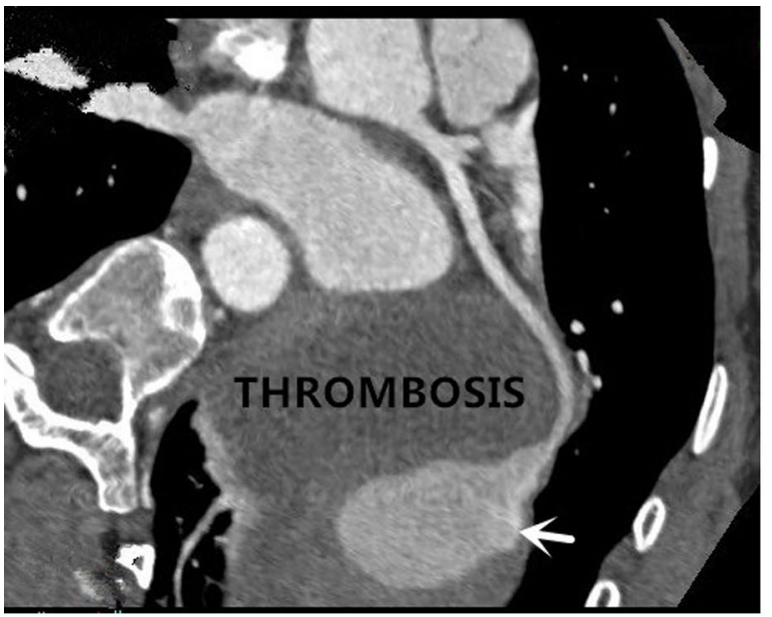

a

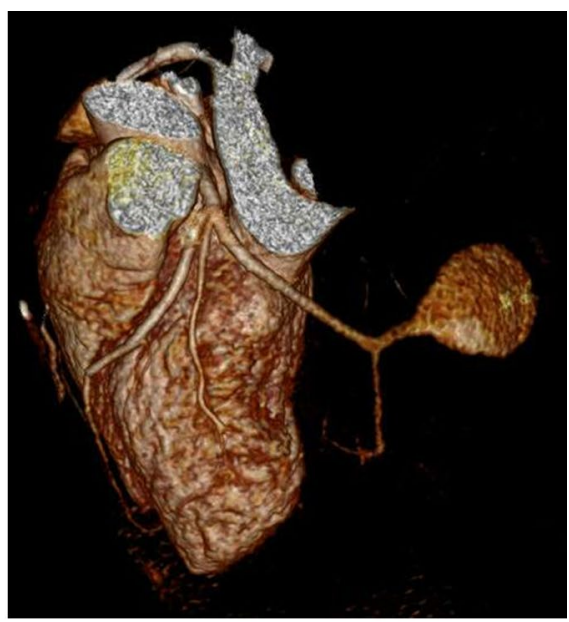

b

Fig. 1 a Coronary computed tomography angiography (CCTA) revealed the giant LCX aneurysm with contrast agent filling observed in the lumen (white arrow) which contained huge intra-aneurysmal thrombosis. b Three-dimensional reconstruction showed the LCX distal pseudoaneurysm

LCX communicating with the pericardium (Fig. 2). The right coronary artery and the left ventriculography were normal. Therefore, a diagnosis of the LCX fistula complicated with false aneurysm was confirmed.

The patient was admitted to the department of cardiac surgery for the LCX repair, partial resection of pseudo aneurysm wall and for coronary aneurysm thrombectomy after all examinations were complete. During the operation, a mass with a size about $25 \times 20 \mathrm{~mm}$ was found in the left rear of the left ventricle, which was located under the epicardium. Then cardiopulmonary bypass was established, a massive thrombi inside the pseudoaneurysm were observed after the left rear of the mass was opened (Fig. 3a). And the total amount of thrombi was about $250 \mathrm{~g}$ (Fig. 3b). After that, the CAF was explored. It was found that the CAF opened on the outer wall of the pseudoaneurysm, with a length of about $3 \mathrm{~mm}$. Finally, the fistula was sutured with 4-0 silk thread and most of the pseudoaneurysm wall was resected. The excised lesions were sent for pathological examination.
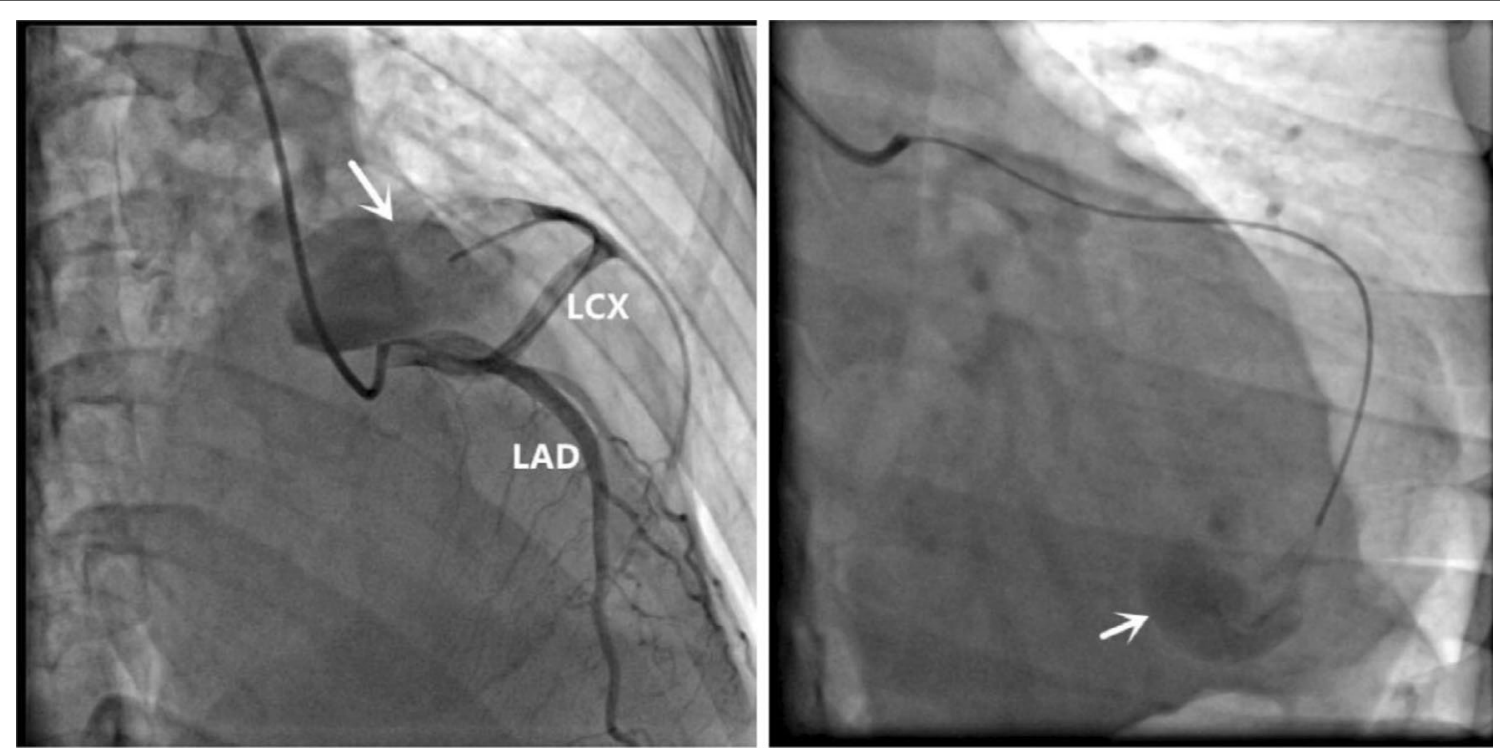

Fig. 2 Selective left coronary artery angiography demonstrating the LCX fistula to the pericardium (white arrow) 


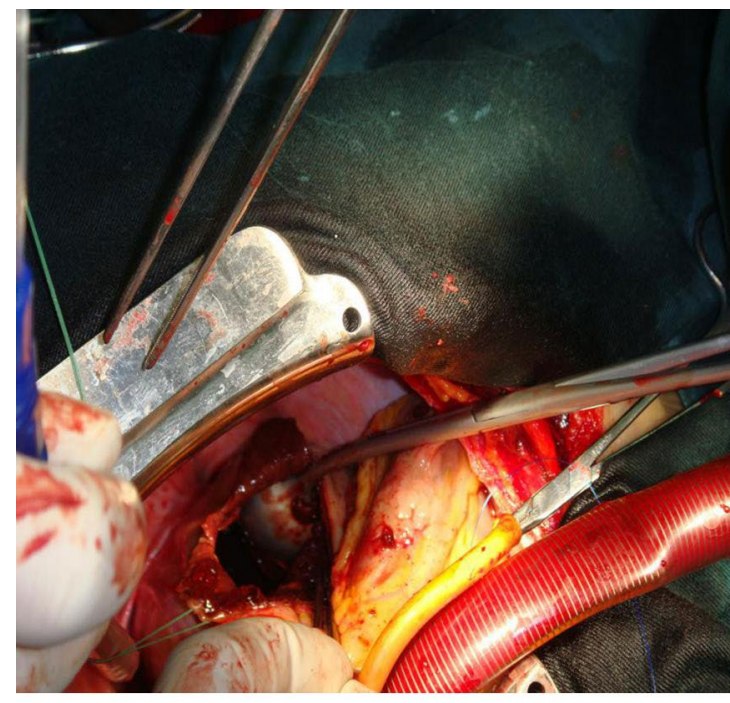

a

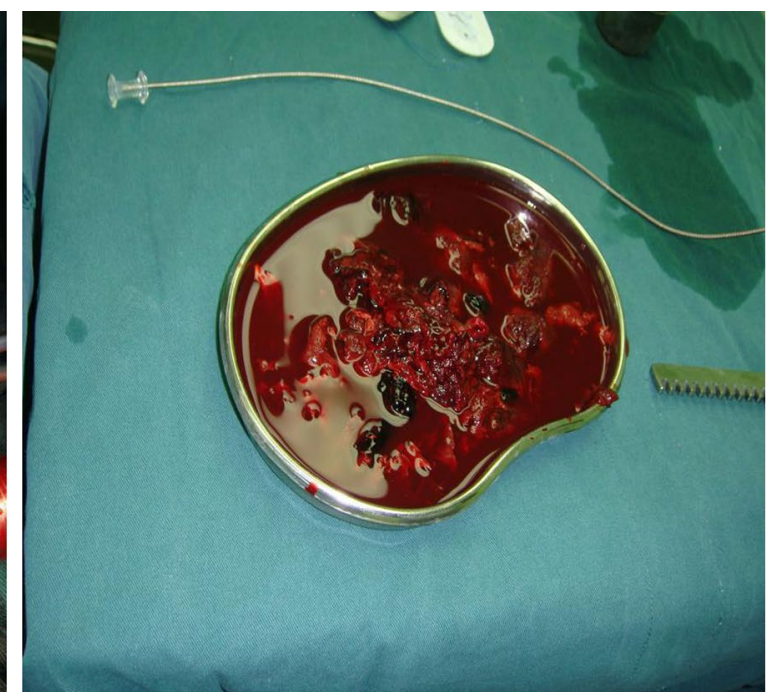

b

Fig. 3 a Surgical view of many old thrombi inside the mass which was located under the epicardium. b Photograph of intra-pseudoaneury small thrombosis after surgery

The pathological diagnosis was pseudoaneurysm and mixed thrombi. Follow-up has been carried out for six years, the patient was in good condition after surgery.

\section{Discussion and conclusions}

Most of the CAFs originate from the right coronary (52\%), arise from the left anterior descending (30\%), date from the left circumflex branch (18\%), and over $90 \%$ of CAFs flow into the right heart [2]. The LCX fistula is very uncommon. The early embryonic development of infection and genetic factors may cause congenital heart disease, which is the primary reason of CAF [1]. Furthermore, coronary atherosclerosis, Takayasu's arteritis or trauma can lead to CAF [3]. In this case, the young patient had no history of coronary artery disease, vasculitis and trauma, which indicated most likely a congenial coronary fistula. Patients with CAF can have different symptoms, such as angina, congestive heart failure, bacterial endocarditis, cardiac arrhythmia or fistula rupture [4]. Although most patients remain commonly asymptomatic for life, CAF can enlarge and rupture [5]. The complications of CAF include myocardial ischaemia, thrombosis and embolism, cardiac failure, atrial fibrillation, rupture, endocarditis/endarteritis and arrhythmias [6]. In our case, the patient showed palpitation and shortness of breath, which is probably due to the contained rupture of the LCX pericardial fistula, followed by the formation of pseudoaneurysm and thrombosis. As the pseudoaneurysm continues to expand, it compresses the surrounding blood vessels, leading to poor reflux, secondary thrombosis and myocardial ischemia. It has also been reported that spontaneous rupture of aneurysmal fistula can cause haemopericardium [6]. Without closure of fistula, this patient could be at risk of pseudoaneurysm rupture and cardiac tamponade.

Conservative treatment, medication, transcatheter intervention and surgery are used to treat CAF [1]. Surgical closure of the CAF was preferred to treat female patients with a fistula that arises from the LCX and ends with a saccular aneurysm are at high risk of rupture, as reported by Said et al. [7], and the perioperative mortality reported with a surgical approach is $2-4 \%$ [4]. The possibility of rupture, a large shunt ratio, and progressive dilatation of the coronary fistulous aneurysm needs early resection of the aneurysm and closure of the fistula [8]. In order to alleviate the symptoms and prevent the rupture of pseudoaneurysm, the patient's fistula was repaired and resected most false aneurysm wall by surgery. So far, the patient has not had any cardiovascular adverse events after the operation.

In conclusion, the huge pseudoaneurysm due to the rupture of left circumflex artery pericardia fistula is extremely rare. Early surgery can reduce the risk of cardiac tamponade because of the continuous fistula and dilated pseudoaneurysm.

\section{Abbreviations}

CAF: Coronary artery fistula; CCTA: Coronary computed tomography angiography; LCX: Left circumflex artery.

\section{Acknowledgements}

Not applicable. 


\section{Authors' contributions}

RW was responsible for guiding and revising the manuscript. ZS and KX were writers of the manuscript. $\mathrm{XL}$ edited and summarized images. All authors read and approved the final manuscript.

\section{Funding}

The case was supported by the Non-profit Central Research Institute Fund of Chinese Academy of Medical Sciences (2019PT320003), the National Natural Science Foundation of China ([2019] GPPH-NSFC-D-2019-27) and the Guizhou Science and Technology Project ([2019]5803). These projects provide a corresponding image processing platform for this case and collect the information of patient.

\section{Availability of data and materials}

The datasets used and/or analysed during the current study are available from the corresponding author on reasonable request.

\section{Declarations}

Ethics approval and consent to participate

Not applicable.

\section{Consent for publication}

Written informed consent was obtained from the patient for publication of this case report and accompanying images. A copy of the written consent is available for review by the Editor of this journal.

\section{Competing interests}

The authors declare that they have no competing interest.

\section{Author details}

'Department of Graduate School, Zunyi Medical University, Zunyi 563000, China. ${ }^{2}$ Department of Radiology, International Exemplary Cooperation Base of Precision Imaging for Diagnosis and Treatment, NHC Key Laboratory of Pulmonary Immune-related Diseases, Guizhou Provincial People's Hospital
No. 83 Zhongshan East Road, Nan Ming District, Guiyang 550002, Guizhou Province, China.

Received: 13 December 2020 Accepted: 10 November 2021

Published online: 27 November 2021

\section{References}

1. Yang Z, Zhang L, Gao J, Cui J, Yuan J, Liu S, Zhou Y, Qiao S. Giant coronary artery fistula complicated with coronary artery aneurysm and acute myocardial infarction: a case report. BMC Cardiovasc Disord. 2020;20(1):136.

2. Sze TL, Abdul Aziz YF, Abu Bakar N, Mohd Sani F, Oemar H. Multimodality imaging of left circumflex artery to coronary sinus fistula. Iran J Radiol. 2015;12(1):e6878.

3. Spektor G, Gehi AK, Love B, Sharma SK, Fuster V. A case of symptomatic coronary artery fistula. Nat Clin Pract Cardiovasc Med. 2006;3(12):689-92.

4. Versaci F, Del Giudice C, Sperandio M, Simonetti G, Chiariello L. A case of coronary artery fistula visualized by 64-slice multidetector CT. Nat Clin Pract Cardiovasc Med. 2009:6(1):57-60.

5. Hijikata S, Sakurai K, Maeba S, Azegami K. Cardiac tamponade due to ruptured coronary-pulmonary artery fistula aneurysm: a case report. Eur Heart J Case Rep. 2020;4(3):1-5.

6. Qureshi SA. Coronary arterial fistulas. Orphanet J Rare Dis. 2006:1:51.

7. Said SA, Schroeder-Tanka JM, Mulder BJ. Female gender and the risk of rupture of congenital aneurysmal fistula in adults. Congenit Heart Dis. 2008;3(1):63-8

8. Kinoshita O, Ogiwara F, Hanaoka T, Tomita T, Yokozeki O, Kai R, Uchikawa S, Kogashi K, Tsutsui H, Imamura H, et al. Large saccular aneurysm in a coronary arterial fistula_a case report. Angiology. 2005;56(2):233-5.

\section{Publisher's Note}

Springer Nature remains neutral with regard to jurisdictional claims in published maps and institutional affiliations.
Ready to submit your research? Choose BMC and benefit from:

- fast, convenient online submission

- thorough peer review by experienced researchers in your field

- rapid publication on acceptance

- support for research data, including large and complex data types

- gold Open Access which fosters wider collaboration and increased citations

- maximum visibility for your research: over $100 \mathrm{M}$ website views per year

At BMC, research is always in progress.

Learn more biomedcentral.com/submissions 